\title{
How was the activity? A visualization support for a case of location-based learning design
}

\section{Javier Melero, Davinia Hernández-Leo, Jing Sun, Patricia Santos, and Josep Blat}

\author{
Dr. Javier Melero, Ms. Jing Sun, Dr. Davinia Hernández-Leo, and Prof. Josep Blat work at the \\ Department of Information and Communication Technologies, Universitat Pompeu Fabra. Dr. Patricia \\ Santos works at the University of the West of England. Address for correspondence: Javier Melero, \\ Universitat Pompeu Fabra, Roc Boronat Street, 138, E-08018, Barcelona, Spain. Email: \\ javimg85@gmail.com
}

\begin{abstract}
Over the last few years the use of mobile technologies has brought the formulation of location-based learning approaches shaping new or enhanced educational activities. Involving teachers in the design of these activities is important because the designs need to be aligned with the requirements of the specific educational settings. Yet, analysing the implementation of the activities with students is also critical, not only for assessment purposes but also for enabling the identification of learning design elements that should be revised and improved. This paper studies a case that applies visualizations to support students' self-assessment and teachers' inquiry of a mobile learning design. The design is a gamified location-based learning activity composed by geolocated questions and implemented with the "QuesTInSitu: The Game" mobile application. The activity was designed by 7 teachers and enacted by 81 secondary education students organized in a total of 23 groups. Log files, gathered from "QuesTInSitu: The Game", provided the data for the visualizations, which represented relevant aspects of the group activity enactment (both time used to answer questions and to reach the geographical zone of the questions, scores obtained per zone, etc.). On the one hand, the visualizations were discussed with the teachers as a learning analytics tool potentially useful to consider when redesigning the activity, if needed. On the other hand, the study shows that the visualizations led students to make a better diagnose of their own activity performance.
\end{abstract}

\section{Introduction}

Advances in mobile technologies release learners from time and spatial limitations and bring new opportunities for supporting and enhancing learning (Rogers, 2008; Wang et al., 2009). In this line, mobile learning (m-learning) allows the creation of location-based learning activities, many of them characterized for including elements based on games (Bohannon, 2010). Some examples are: "Environmental Detectives" (Klopfer \& Squire, 2008) that investigates a simulated chemical spill on a college campus; "Mad City Mystery" (Squire \& Jan, 2007) that investigates a death caused by murder, suicide or the combination of several interacting toxic chemicals; "Reliving the Revolution" (Schrier, 2009), aiming to teach historical thinking and inquiry skill around the Battle of Lexington; Savannah (Facer et al., 2004), focused on exploring the opportunities and risks to being lions; Alien Contact! (Dunleavy et al., 2009), intended to teach maths, language arts, and scientific literacy skills by playing collaboratively; Frequency 1550 (Huizenga et al., 2009) that helps students playfully acquire historical knowledge of medieval Amsterdam; and Blåtannkoden (Ceipidor et al., 2009), focused on solving different riddles related to the topics of a museum of telecommunications. However, these studies did not report teachers' involvement in the design of these location-based learning activities.

It is clear that teachers want to use m-learning applications in their teaching practice (Ozdamli \& Uzunboylu, 2014). However, it is important that teachers are involved in the design of the m-learning activities if they have to be aligned with the requirements of their particular educational situations (Tornero et al., 2010; Yang, 2005). Besides, the potential of the educational improvement is not fully exploited if teachers and students neglect a careful reflection on the activity enactment. Equipping teachers with tools to inquire into the execution of their own designs is crucial to enable them the identification of design elements that need to be reinforced and revised in future editions of the activity (Kelly, 2003). Besides, the provision of tools to facilitate students' self-assessment can strengthen learning and promote the development of meta-cognitive skills (Brown et al., 2013). Using learning analytics as strategies to measure, collect, analyse and report data about learners and their contexts, seem to be the appropriate approach to base the features behind those tools (Pardo \& Siemens, 2014; Ellis, 2013). This paper aims at contributing towards an improved understanding of what type of data and representations can effectively support inquiry and self-assessment in the specific domain of locationbased learning, and to what extent the same data and representations can serve well both purposes. 
In particular, the paper proposes and studies a set of learning analytics visualizations as a twofold tool to support teachers' design inquiry and students' self-assessment. The study focuses on a design of a gamified location-based learning activity. The design was created by a secondary school teachers' team following a puzzle-based game model (Melero \& Hernández-Leo, 2014; Melero et al., 2013). Several reasons are behind the use of puzzles game boards as design elements to create this type of activities. On the one hand, board games offer an intuitive conceptualization to design location-based learning activities (Nicklas, 2001; Schlieder et al., 2006). If aligned with course objectives and students' profiles, puzzlebased activities can engage students in the subject topics and foster their analytical and memory skills (Bottino et al., 2007). On the other hand, the use of game elements can immerse learners in meaningful and enjoyable learning, encouraging active learning, promoting the exploration of information, and activating prior learning to advance forward (Oblinger, 2004, Ke, 2008, Arnab et al., 2014).

A total of 81 secondary school students (males and females, with an average of 17 years old), divided into 23 groups, performed the gamified location-based learning activity using "QuesTInSitu: The Game", a mobile application implementing the teachers' design. During the activity, the application gathered information about students' interactions with the system and their locations. Several visualizations were designed considering the data extracted from the log files of the mobile application. Visualization techniques have been developed as a popular method to help people quickly grasp and effectively understand the required information. The goal of information visualization is to amplify human cognition, facilitating the identification of patterns, trends and anomalies in ways that would be much harder to accomplish from numerical datasets or textual descriptions (Card, MacKinlay \& Schneiderman, 2009). In this study, the applied visualizations were designed as a representation of learning analytics to report data about students' performance in the designed activity. The visualizations were shown both to teachers and students to analyse their support for the two purposes of supporting inquiry (teachers) and self-assessment (students).

This section has motivated the research presented in this paper, including a discussion of the relevant related literature that frames the formulation of the research. The remainder of the paper is structured as follows. Next section describes the context of the study, including the gamified location-based learning design created by secondary education teachers and its implementation using "QuesTInSitu: The Game". This is followed by a presentation of the learning analytics visualizations under study. Then, the methodology section is introduced including the description of the instruments used and the number of participants (teachers and students) involved in the study. The next two sections describe the results on teachers' analysis of the visualization support for design inquiry and the visualizations' effects on the students' activity performance self-diagnosis, respectively. Finally, the paper concludes key aspects that emerge from the research and describes future steps.

\section{Teachers' design of a gamified location-based learning activity}

The activity was organized in conjunction with a semi-public High School in l'Hospitalet, a workingclass zone situated in the Barcelona metropolitan area. A metaphor based on "puzzle board games" has been used to design the gamified location-based learning activity (Melero et al., 2013). This metaphor considers a conceptual model, and the associated binding, for allowing teachers' the design of technology-supported puzzle games including virtual and physical objects (Melero et al., 2014). In particular, the design of these gamified location-based learning activities consists of routes containing geolocated questions that include game elements such as hints, feedbacks, bonus, and score mechanisms. Besides, the puzzle-based game metaphor includes the following elements: a) Level, a particular geographical area or zone where the geolocated questions are placed; b) Puzzle, group of questions associated to a level; c) Slots, geolocated questions designed for a particular puzzle; and d) Puzzle pieces, options associated to each geolocated question.

\section{Game description}

The gamified location-based learning activity was conceived as a transversal and interdisciplinary learning experience for students (i.e. the activity did not have a direct impact on students' outcomes to specific subjects). The purpose of the learning activity was to make students familiar with the city of l'Hospitalet and its heritage (i.e. most of the students do not live in the city of the school). In particular, the activity was designed in such a way that questions addressed different subject topics related to the city (i.e. maths, music, natural sciences, geography, art history). For this reason, seven expert teachers in different disciplines were involved in the activity design. In particular, the teachers designed 10 levels containing a total of 58 geolocated questions, some of them including hints designed as suggestions to help students find the correct answers. When all the questions for a particular level were correctly 
answered, the students were rewarded with extra bonus scores. Also, the teachers designed specific positive and negative amounts of scores associated to the right and wrong answers, respectively.

The designed activity was deployed by "QuesTInSitu: The Game” (see Figure 1). "QuesTInSitu: The Game" is a mobile application compliant to the conceptual model for puzzle-based game design proposed by Melero et al. (2014). In particular, the students using the application have to go to specific geolocated zones. Once the students reach the geolocated zones, questions automatically appear. Somehow similarly to jigsaw puzzles, each question can be solved as many times as necessary until reaching a correct solution. Positive and negative scores reflect the correct and wrong answers by the students, and hints can be accessed if the students need some kind of help to solve the questions. Finally, the teachers specified diverse routes for the same gamified location-based learning activity, each one starting in a different initial geographical point and following a particular path.
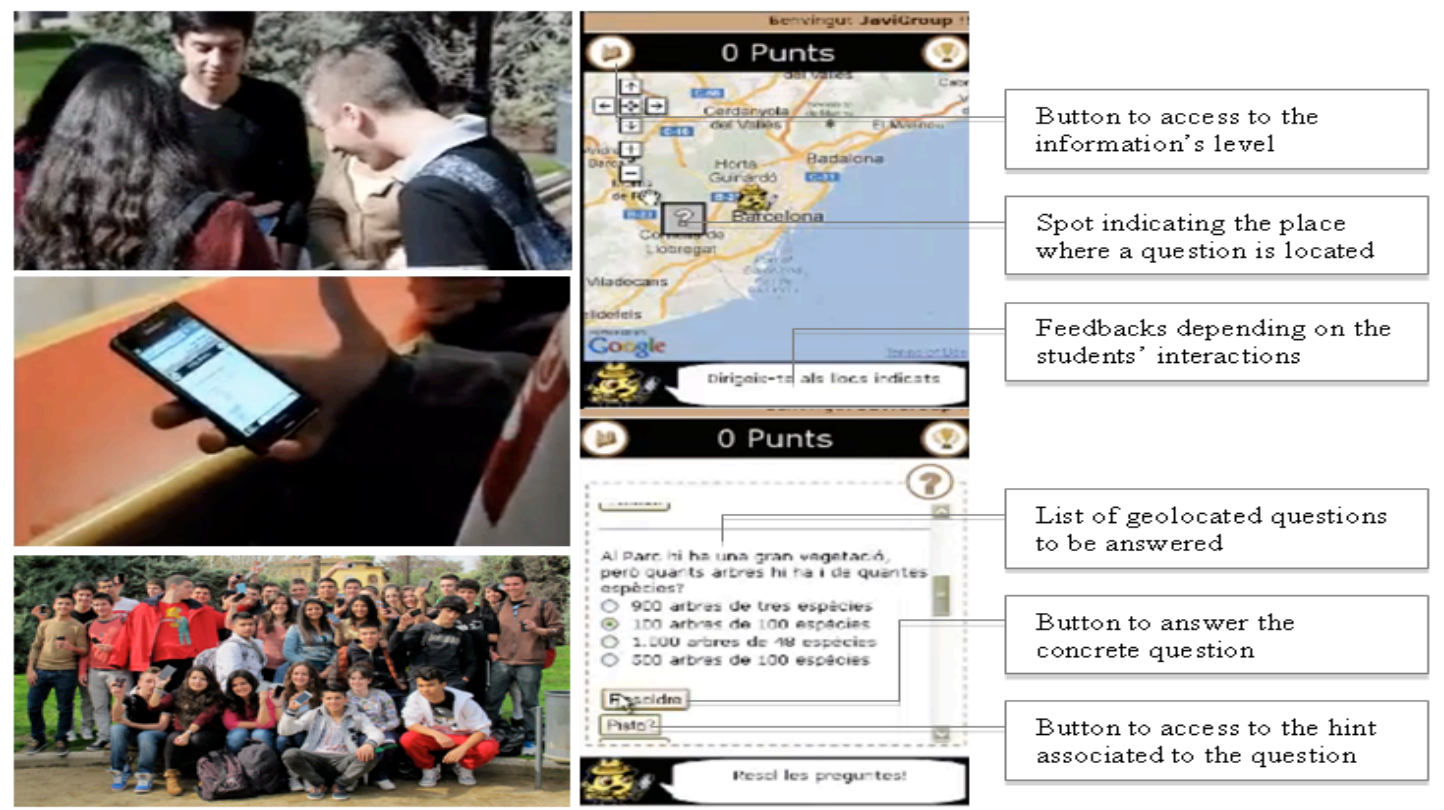

Figure 1. Pictures of the students performing the activity and screenshots of "QuesTInSitu: The Game"

\section{Visualizing the students' activity performance}

Log files of "QuesTInSitu: The Game" gathered relevant data about the interactions from 23 groups of students with the mobile application. The data includes: both time used to answer questions and to reach the geographical zone of the questions, number of attempts to solve each questions, and scores obtained per question. Considering this information, several learning analytics visualizations were designed as a twofold tool to allow (1) the teachers inquire into the enactment of their m-learning activity design, and (2) facilitate the students' self-assessment. In concrete, the visualizations were divided into several sections:

- General information: This section presents the title of the game, the date when the activity was performed, the group name and the group members for the particular visualization, the total score obtained by the group, and a description of the game rules (see Figure 2).

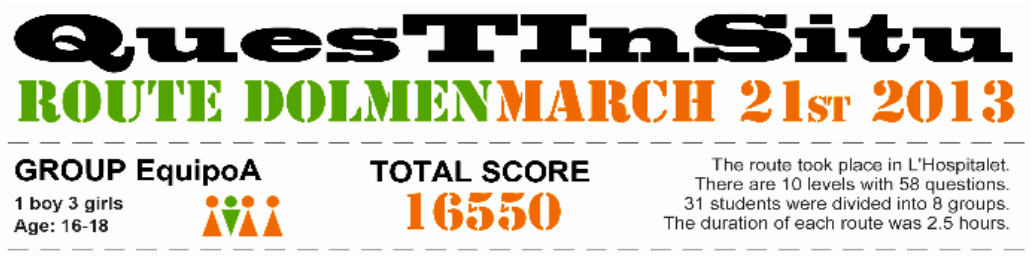

Figure 2: Example of general information

- Time used: A clock metaphor has been used for showing the time dedicated of the students' group to performing the activity. One sector represents the time used to navigate from one geographical zone to another, while the other sector stands for the time used to solve the questions of a particular zone. Also, the zones are shown sequentially according to the route followed (see Figure 3). 


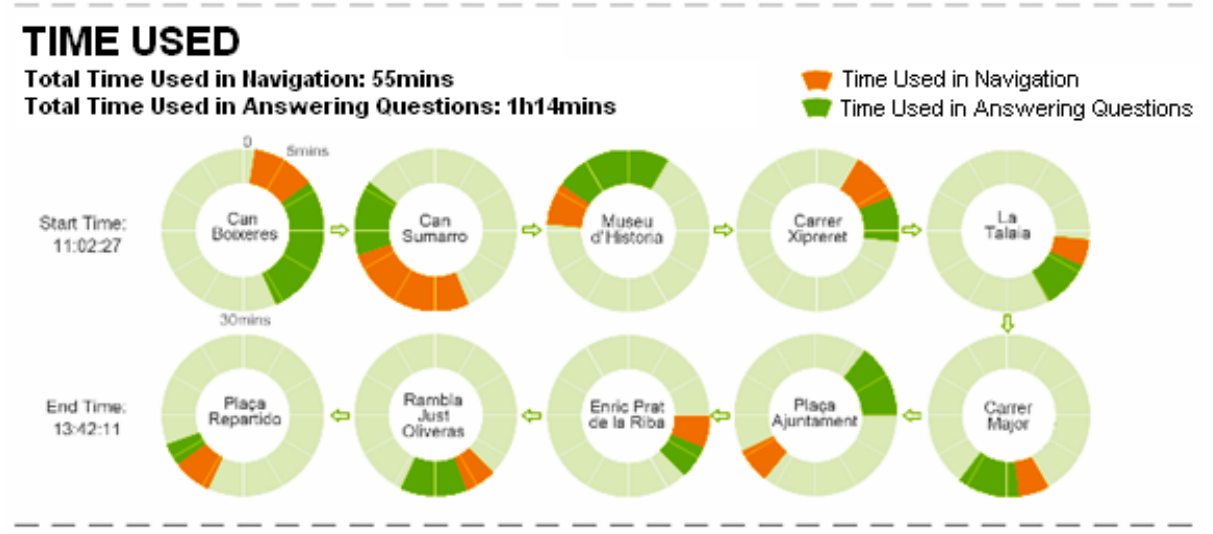

Figure 3: Example of time used visualization

- Track: A map visualization shows the route of the group (dotted line) and the state of every geographical zone (completed or uncompleted) (see Figure 4).

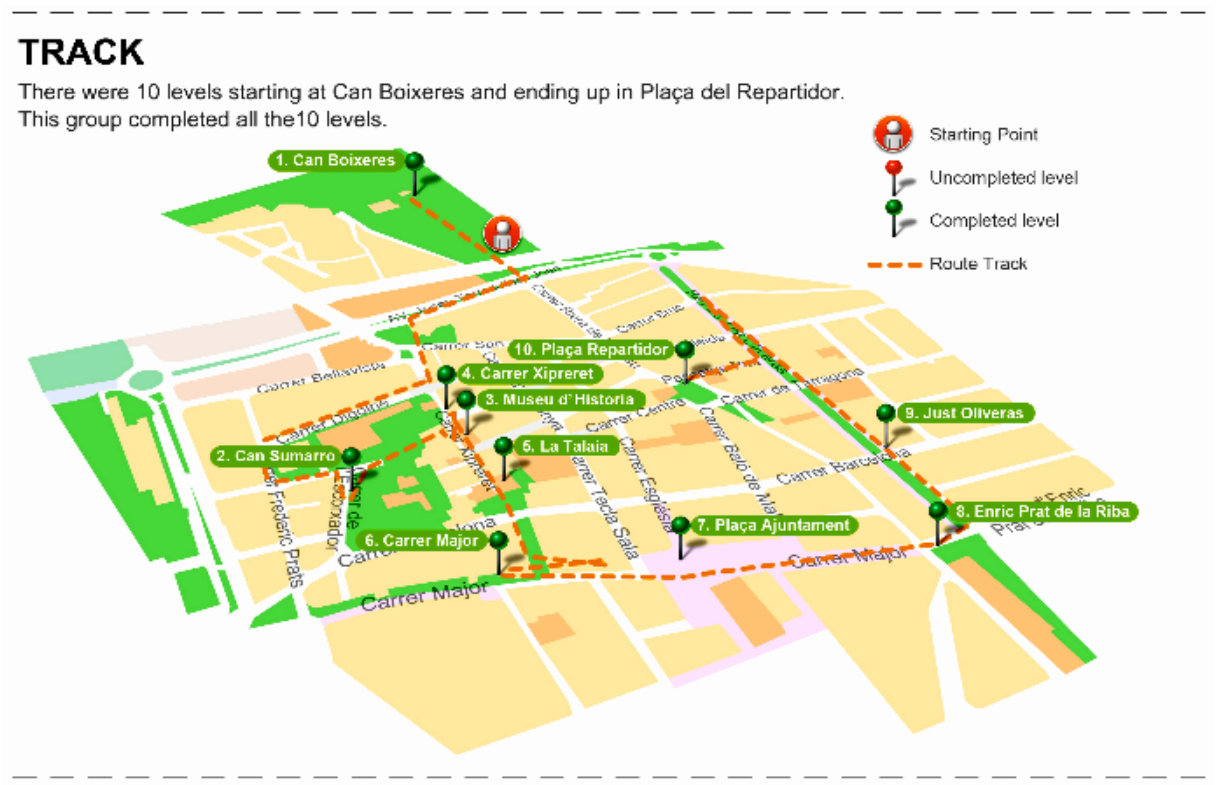

Figure 4: Example of track visualization

- Frequency: Since the students can answer as many times as necessary each question, this visualization depicts the amount of attempts that the students have accessed to each question until they submitted the correct answer. A reference line was set on the lowest frequency, meaning the students gave the correct answer in the first attempt. In addition, a point was set to represent the question that the students did not ever give a correct answer (see Figure 5).

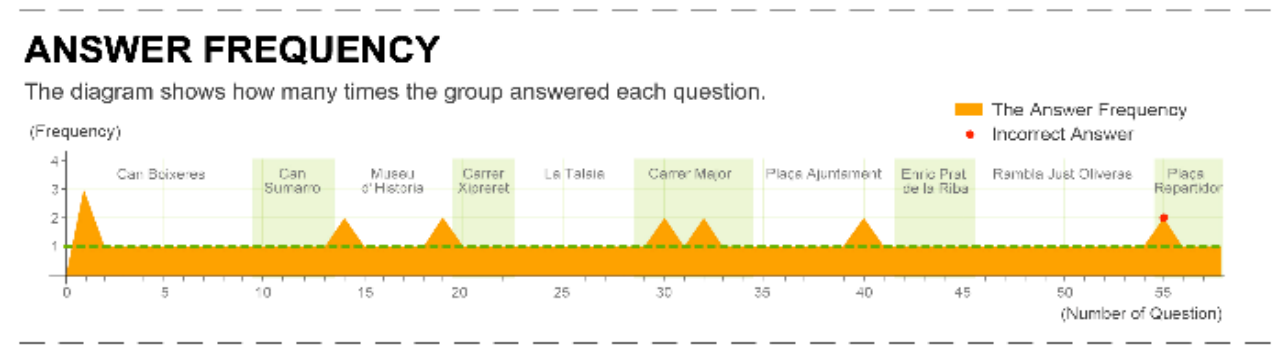

Figure 5: Example of answer frequency visualization

- Score: Considering the scores and bonus designed by the teachers, this visualization shows the scores obtained by the students for each question. The coloured area stands for the score the group got from each question and the dotted line shows the highest score that can be obtained for each question (see Figure 6). 


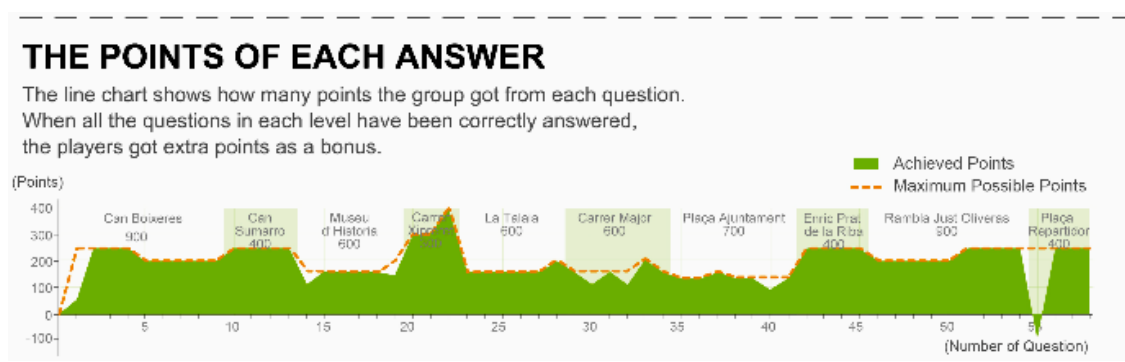

Figure 6: Example of score visualization

\section{Methodology}

An evaluation including data collection from 3 teachers (out of the 7 involved in the activity design) and the 81 secondary education students was carried out. Different instruments have been used to gather quantitative and qualitative data, in order analyse to what extent the proposed learning analytics visualizations are useful to support inquiry and self-assessment, respectively.

\section{Instruments for evaluating teachers' opinions}

A discussion group with the teachers was scheduled three weeks after the enactment of the activity. Three out of the seven teachers involved in the design of the activity were available to participate in the discussion group. During the session, each teacher was provided with an example of the visualizations (Figures 2-6), and a document showing the results obtained from the students' opinions after performing the activity. In order to evaluate the teacher's opinions, we recorded the discussions and transcribed their comments. Besides, at the end of the session, each teacher filled out a questionnaire (available at http://www.javiermelero.es/bjet questionnaire teachers.pdf) in which they were asked to explain, from their perspective, what types of analytics and visualizations would be most relevant for them in this type of learning activities. In particular, the questionnaire consisted of a Rank-in-Order question in which the teachers had to rank the importance of having information visualizations of: a) students achieving correct answers, b) time used to answer questions, c) correctly answering questions at the first attempt, d) time used for orientation, e) obtained score, f) amount of attempts to correctly answer the questions, g) all students collaborating to solve the questions, and h) the place where the students are when they solve questions. The data obtained from the teachers questionnaires and the discussion group were triangulated and analysed to gain insights into the most important data depicted in the learning analytics visualizations to support teachers' inquiry (see Figure 7).

\begin{tabular}{|c|c|c|}
\hline Instruments & Gathered data & Focus and method of analysis \\
\hline $\begin{array}{l}\text { Teachers' Questionnaire [qX], } \\
\text { where X is the letter assigned to a } \\
\text { teacher, from A to C }\end{array}$ & $\begin{array}{l}\text { Answers by teachers to Rank-in- } \\
\text { Order questions regarding the } \\
\text { relevance of different types of } \\
\text { information that can be collected } \\
\text { and visualized in m-learning } \\
\text { activities }\end{array}$ & \multirow{2}{*}{$\begin{array}{l}\text { Qualitative analysis (driven by } \\
\text { categories) to understand teachers' } \\
\text { opinions on the design and } \\
\text { usefulness of the visualizations as } \\
\text { a teachers' inquiry tool }\end{array}$} \\
\hline $\begin{array}{l}\text { Discussion group }[\mathrm{dX}] \text {, where } \mathrm{Y} \text { is } \\
\text { the letter assigned to a teacher, } \\
\text { from } \mathrm{A} \text { to } \mathrm{C}\end{array}$ & $\begin{array}{l}\text { Record of direct observations } \\
\text { taken during a discussion group } \\
\text { with teachers. The discussion was } \\
\text { organized around the topics of } \\
\text { research (how teachers valued the } \\
\text { characteristics of the } \\
\text { visualizations, issues and ideas for } \\
\text { improvement) }\end{array}$ & \\
\hline
\end{tabular}

Figure 7: Summary of instruments used for evaluating teachers' opinions

Instruments for evaluating students' opinions

Besides, this study also aimed at evaluating whether the learning analytics visualizations facilitate the students with a better diagnose of their own performance. Just after finishing the gamified location-based learning activity, the students answered a pre-questionnaire, without using the visualizations, about their performance. Then, $2 / 3$ weeks after the activity, the students answered a post-questionnaire using the visualizations. Both pre- and post- questionnaires contained the same questions (available at http://www.javiermelero.es/bjet questionnaire students.pdf) concerning different aspects of students' activity performance (i.e. zones in which they perceived that their performance was better/worst). Besides, these questions were corrected using the data collected by the "QuesTInSitu: The Game" log files as the objective standard to measure the accuracy of the diagnosis (see Figure 8). In particular, both 
questionnaires consisted of: a) six multiple-choice questions focused on the score and time used to answer questions and to navigate (i.e. In which level do you think you perform better (worse)?, "In which level do you think you get the highest (lowest) score?", "In which level do you think you used more (less) time when answering questions?"); b) 1 question was asked to assess their self-diagnosis of the overall learning performance (i.e. "How many questions do you think that you have correctly answered?"); and c) one open question to give their opinion about the activity. Since the score, time used or frequency of answers can be quite similar in different levels, the standard value (correct answer obtained from the log files) was equipped with 2 alternative correct answers, which are the approximate answers. When the student gave the approximate answer, he/she would obtain half score in this question.

\begin{tabular}{l|l|l}
\hline \multicolumn{1}{c|}{ Instruments } & \multicolumn{1}{c|}{ Gathered data } & \multicolumn{1}{c}{ Focus and method of analysis } \\
\hline \multirow{3}{*}{ Log files } & $\begin{array}{l}\text { Quantitative data capturing } \\
\text { students' interactions with the }\end{array}$ & \\
& $\begin{array}{l}\text { QuesTInSitu: The Game using } \\
\text { mobile phones }\end{array}$ & $\begin{array}{l}\text { Statistical analysis to evaluate } \\
\text { students' diagnose of their own }\end{array}$ \\
\cline { 1 - 2 } $\begin{array}{ll}\text { Students' pre- and post- } \\
\text { questionnaire }\end{array}$ & $\begin{array}{l}\text { Quantitative answers by students } \\
\text { to multiple-choice questions about } \\
\text { their perception of performance by }\end{array}$ & $\begin{array}{l}\text { Log files were used to validate } \\
\text { students' answers from both pre- } \\
\text { and post- questionnaires }\end{array}$ \\
& $\begin{array}{l}\text { game levels in terms of score and } \\
\text { time, before and after looking at } \\
\text { the visualizations. }\end{array}$ & \\
\hline
\end{tabular}

Figure 8: Summary of instruments used for evaluating students' opinions

Following two sections describes the main results obtained from the evaluations with teachers and students, respectively.

\section{Results on teachers' opinions}

In general, the visualizations seem to contain a lot of information that cannot be analysed in a short time [C]. However, the teachers highlighted the importance of visualizations to provide objective information. In particular, the teachers indicated that the main source they previously considered for a redesign of the activity was only based on the observations that one of the teachers took during the m-learning activity $[\mathrm{dA}, \mathrm{dB}, \mathrm{dC}]$. This type of activities can be repeated and reused in several editions. Then, these observations might be enough for a person who has been always involved in the designs of the route. However, for a new teacher, who knows the environment (in this case, the city) but has not participated in previous designs of the activity, the information provided by the visualizations could be essential to detect weaknesses and strengths and proposed meaningful changes in the activity. [dC].

Overall, the data from the visualizations has been considered a good approach to assess the redesign of the activity. One of the teachers indicated that the visualizations can help to identify the elements that have to be modified (e.g. scoring mechanisms or routes' paths) and confirmed the elements that should be kept as they were initially designed $[\mathrm{dC}]$. Focusing on the different types of visualizations, the time used (Figure 3) was considered of great importance because the expected time used to perform the activity, when designing the activity, could differ from the reality $[\mathrm{dA}, \mathrm{dB}, \mathrm{dC}]$. Besides, since each route follows different paths, the information about the time used could suggest the most efficient routes [dB]. It is interesting that two of the teachers, when answered the questionnaire, indicated the time used to answer questions as one of the less important elements to consider [qA, qC]. This result could be because this information is useful to design the activity's routes but not for evaluating the students' activity performance. In this sense, the teachers considered the frequency (Figure 5) and score (Figure 6) visualizations essential to evaluate the students' performance, and to discriminate the most difficult questions are $[\mathrm{dA}, \mathrm{dB}, \mathrm{dC}]$. In particular, on the one hand, by looking at the frequency visualization (Figure 5), teachers were able to identify the most problematic questions (i.e. those in which students performed more attempts). And, on the other hand, teachers could detect the questions in which students obtained higher and lower scores by looking at the score visualization (Figure 6). Nevertheless, the teachers considered the track visualization (Figure 4) the less useful to for the redesign of the activity.

One of the aspects mentioned during the discussion group was the importance of having aggregate data of all the groups of students $[\mathrm{dB}]$. Specifically, the three teachers highlighted the need of having visualizations with aggregate data about the answers' frequency (Figure 5) and score (Figure 6) of all the groups of students. The main reason was that this information could be very relevant to have an impression about the questions that have been more difficult $[\mathrm{dA}, \mathrm{dB}, \mathrm{dC}]$. However, having the aggregate data of the time used (Figure 3) was considered less important since each group follows different routes $[\mathrm{dA}, \mathrm{dB}, \mathrm{dC}]$. 
Apart from the data shown in the visualizations, the teachers also highlighted the importance of considering the emotional side of the students: the degree of satisfaction, how the hints influenced the students' performance, what the students liked most and what they learned, $[\mathrm{dA}, \mathrm{dC}]$, how the students used the information provided by the environment to answer the questions [qA, qB, qC], and whether all the members' of the group participated in solving the questions [qA, $\mathrm{qB}$ ]. In this line, the information gathered from the questionnaires filled by the students after the activity was very interesting to the teachers because this allowed them to identify the complaints about having to walk too much or having to carry their backpacks [dA, dC]. Besides, the data obtained from the students' questionnaires was useful to confirm the teachers' feelings about the designed activity [dB]. For example, while performing the activity, some of the teachers observed that there were groups of students that did not consult the information associated to the different levels $[\mathrm{dB}]$. The teachers could check that this observation was reflected in the opinions obtained from the student's questionnaires. This result might indicate that the information associated to the geographical zones was not probably the focus of the students. Therefore, this result made the teachers think that the level's information should appear automatically before showing the questions to encourage the students to read it $[\mathrm{dB}]$.

Finally, the results of the questionnaires filled by the students were also useful to consider the redesign of some of the elements of the activity. In this line, some of the teachers checked that one of most controversial element was the subtraction of scores; the teachers were surprised that students did not like explicitly loosing scores when failing the questions $[\mathrm{dB}, \mathrm{dC}]$. In this sense, the teachers suggested that would be important to better explain the rules of the activity to the students $[\mathrm{dB}]$, or exactly understand the reasons behind this result in order to reconsider the design of the subtracted scores [dC]. Teachers suggested that maybe the scores should be consistent across all the levels of the game or maybe the students are used to play games in which scores are not subtracted [dC]. Furthermore, the teachers highlighted the importance to know the preferences of the students while playing games to redesign the game $[\mathrm{dC}]$. In this line, the teachers discussed that despite of subtracting scores prevents trial and error [dA], it is crucial to take into account the audience to whom the activity is intended with the aim that the students enjoy the activity and have fun $[\mathrm{dC}]$. The teachers considered that a learning associated with a positive feeling leads the students to remember better what they have learned [dC]. In this sense, the teachers suggested that a possible solution would be to define specific amount of positive scores, depending on the number of attempts when solving a question, instead of subtracting scores $[\mathrm{dC}, \mathrm{dB}]$. In this line, the information gathered from the questionnaires was also considered valuable to teachers' inquiry. But, further research involves how this gathered data could be visualized.

\section{Results on diagnosis from the students' opinions}

For the evaluating the students' self-assessment, all the pre- and post-questionnaires were analysed. In particular, we cleaned the dataset by deleting the data of the students that only completed one out of the two questionnaires. Therefore, pre- and post-questionnaire scores from 63 students were obtained (out of the 81 who completed the game). Then, a Kolmogorov-Smirnov test was ran and got the sample with normal distribution. Since the aim of this evaluation was to compare the different diagnosis made by the same students, a dependent t-test was run to test the score differences between pre- and postquestionnaires (see Figure 9).

\begin{tabular}{|c|c|c|c|c|c|c|c|c|}
\hline \multicolumn{9}{|c|}{ Paired Samples Statistics } \\
\hline & & \multicolumn{2}{|l|}{ Mean } & $n$ & \multicolumn{2}{|c|}{ Std. Deviation } & \multicolumn{2}{|c|}{ Std. Error Mean } \\
\hline \multicolumn{2}{|l|}{ Without } & \multicolumn{2}{|l|}{2.968} & 63 & \multicolumn{2}{|c|}{1.3133} & \multicolumn{2}{|r|}{.1655} \\
\hline With & & 3.706 & & 63 & \multicolumn{2}{|c|}{1.5904} & \multicolumn{2}{|r|}{.2004} \\
\hline \multicolumn{9}{|c|}{ Paired Samples Correlation } \\
\hline & & \multicolumn{2}{|r|}{$\bar{n}$} & \multicolumn{2}{|c|}{ Correlation } & & \multicolumn{2}{|r|}{ Sig. } \\
\hline \multicolumn{2}{|c|}{ Without \& With } & \multicolumn{2}{|r|}{63} & \multicolumn{2}{|c|}{.216} & & \multicolumn{2}{|r|}{.090} \\
\hline \multicolumn{9}{|c|}{ Paired Samples Test } \\
\hline & \multicolumn{5}{|c|}{ Paired Differences } & \multirow{3}{*}{$t$} & \multirow{3}{*}{$d f$} & \multirow{3}{*}{ Sig. (2-tailed) } \\
\hline & \multirow[t]{2}{*}{ Mean } & \multirow{2}{*}{$\begin{array}{c}\text { Std. } \\
\text { Deviation }\end{array}$} & \multirow{2}{*}{$\begin{array}{c}\text { Std. Error } \\
\text { Mean }\end{array}$} & \multicolumn{2}{|c|}{$\begin{array}{c}95 \% \text { Confidence Interval } \\
\text { of the Difference }\end{array}$} & & & \\
\hline & & & & Lower & Upper & & & \\
\hline Without-With & -.7381 & 1.8313 & 2307 & -1.1993 & -.2769 & -3.199 & 62 & .002 \\
\hline
\end{tabular}

Figure 9: T-Test results

The result was, with the data of 63 students, the students made significant higher score in the postquestionnaire with visualizations $(\mathrm{M}=3.71 \mathrm{SD}=1.59)$ than in the pre-questionnaire without visualizations 
$(\mathrm{M}=2.97 \mathrm{SD}=1.31), \mathrm{p}=.002 \mathrm{p}<0.05$. This means that students using visualizations made better diagnosis of their actual measured global performance.

\section{Conclusions}

The research presented in this paper aims to gain insights when providing learning analytics visualizations as a tool for teachers' inquiry and students' self-assessment in location-based m-learning activities. As a whole, the paper has presented a case of a gamified location-based learning design consisting in geo-located questions. "QuesTInSitu: The Game" was used to enact teachers' design, and several visualizations were provided to both teachers and students considering the data extracted from log files of the mobile application.

One of the aims of this study was to evaluate the use of visualizations with teachers as an approach for redesigning m-learning activities. In this sense, the proposed visualizations has allowed teachers to identify which learning design elements should be revised and improved. In concrete, the teachers noticed two main issues. On the one hand, the subtracting scores should be redesigned, avoiding the use of negative scores and using proportional positive scores in relation to the attempts when solving each question. On the other hand, the teachers proposed to automatically show the information associated to each geographical point before answering the geo-located questions in order to encourage the students to read this information. However, the described visualizations presents the limitation of being represented in a paper-based document instead of being integrated a digital environment. This limitation has restricted teachers to interact with visualizations in a more friendly way. However, this has not been a drawback to conclude that the visualizations used are a good mechanism to represent and analyse objective data obtained from the enactment of their designed m-learning activity.

The visualizations include too much information to be analysed on the fly during the activity or in short amount of time. In this line, it would be interesting to identify what visualizations are the most essential so they offer more dynamic teacher-led inquiring tools. The time used visualization has been considered of great importance to evaluate the overall design of the activity's routes, whilst the frequency and score visualizations are crucial to evaluate the students' performance and identify the most problematic questions. Besides, in this type of learning activities, the teachers highlight the usefulness of providing visualizations containing aggregate data from all the students' groups. Having aggregate data is considered useful to easily identify trends and the most problematic questions. Particularly, it would be great to have the aggregate data from the frequency and score visualizations. Besides, apart from having the objective data obtained from the learning analytics visualizations, teachers also highlight the importance of knowing the students' opinion in order to analyse whether they enjoy the activity, learn new concepts and have fun. These aspects are relevant to the teachers since they believe that those students who associate their learning with a positive feeling will remember better what they have actively learned. Thus, further research includes integrating students' opinions in the visualizations to help the teachers easily identify the main issues when enacting their design.

On the other hand, this research work has also proposed visualizations as an approach to facilitate students' self-assessment. In this sense, the use of visualizations by students aims to strengthen their learning and help their development of meta-cognitive skills. Results from the evaluation have shown that students using visualizations make a better diagnosis of their own performance in terms of identifying the most problematic questions and zones. Yet, further research is still needed in order to know which elements of the visualization are more useful to the students.

Therefore, this study implies that the provision of learning analytics visualizations can have a positive impact in teachers' designs and students' self-assessment. However, further research is still needed in order to provide both teachers and students with meaningful and easy-to-use technological approaches. Several further research lines have been identified: a) making visualisations more manageable for both students and teachers to use; b) integrating visualizations techniques of learning analytics in "QuesTInSitu: The Game"; c) gathering students' opinions that occurred during game play and associating them to specific game elements (e.g. hints, questions, level's content); d) providing to both students and teachers with overviews of visualizations that could be analysed in a short amount of time (e.g., real-time analytics to be considered on the fly during the activity); and e) providing meaningful visualization techniques for showing aggregate data on the performance of this type of location-based learning activities. 


\section{Acknowledgments}

This research has been partially funded by the Spanish Ministry of Economy and Competitiveness in the EEE Project (TIN2011-28308-C03-03). The authors would also like to thank the teachers and the students of the Dolmen Educational Centre in L'Hospitalet.

\section{References}

Arnab, S., Lim, T., Carvalho, M.B., Bellotti, F., de Freites, S., Louchart, S., Suttie, N., Berta, R., de Gloria, A., (2014). Mapping learning and game mechanisms for serious games analysis, British Journal of Educational Technology, doi:10.1111/bjet.12113.

Bohannon, R. (2010). Location, Location, Location: An Exploration of Location-Aware Learning Games for Mobile Devices. In the Proceedings of Society for Information Technology \& Teacher Education International Conference, Chesapeake, VA.

Bottino, R.M., Ferlino, L., Ott, M., \& Tavella, M. (2007). Developing strategic and reasoning abilities with computer games at primary school level. Computers \& Education, 49(4), 1272-1286.

Brown, G.A., Bull, J., \& Pendlebury, M. (2013). Assessing student learning in higher education. Routledge.

Card, S.K., MacKinlay, J.D. \& Schneiderman, B. (2009). Information Visualization. Human-Computer Interaction: Design Issues, Solutions, and Applications, 181.

Ceipidor, U. B., Medaglia, C. M., Perrone, A., De Marsico, M., \& Di Romano, G. (2009). A museum mobile game for children using QR-Codes. In Proceedings of the 8th International Conference on Interaction Design and Children (pp. 282-283). Como, Italy.

Dunleavy, M., Dede, C., \& Mitchell, R. (2009). Affordances and limitations of immersive participatory augmented reality simulations for teaching and learning. Journal of Science Education and Technology, 18(1), 7-22

Ellis, C. (2013). Broadening the scope and increasing the usefulness of learning analytics: The case for assessment analytics. British Journal of Educational Technology, 44(4), 662-664.

Facer, K., Joiner, R., Stanton, D., Reid, J., Hull, R., \& Kirk, D. (2004). Savannah: mobile gaming and learning?. Journal of Computer Assisted Learning, 20(6), 399-409.

Huizenga, J., Admiraal, W., Akkerman, S., \& ten Dam, G. (2009). Mobile game-based learning in secondary education: engagement, motivation and learning in a mobile city game. Journal of Computer Assisted Learning, 25(4), 332-334

Ke, F. (2008). A case study of computer gaming for math: Engaged learning from gameplay? Computers \& Education, 51(4), 1609-1620.

Kelly, A.E. (2003). Research as design. Educational Researcher, 32(1), 3-4.

Klopfer, E., \& Squire, K. (2008). Environmental Detectives - the development of an augmented reality platform for environmental simulations. Educational Technology Research and Development, 56(2), 203-228.

Melero, J., \& Hernández-Leo, D. (2014). A Model for the Design of Puzzle-based Games including Virtual and Physical Objects. Journal of Educational Technology \& Society, 17(3), pp. 192-207.

Melero, J., Santos, P., Hernández-Leo, D. \& Blat, J. (2013). Puzzle-based Games as a Metaphor for Designing Situated Learning Activities. In the Proceedings of the 6th European Conference on Games Based Learning, 3-4 October 2013, Porto, Portugal.

Nicklas, D. Pfisterer, Ch., \& Mitschang, B. (2001). Towards Location-based Games. In Proceedings of the International Conference on Applications and Development of Computer Games in the 21st Century, 22-23 November 2011, Hongkong Special Administrative Region, China.

Oblinger, D. (2004). The next generation of educational engagement. Journal of Interactive Media in Education, 8, 1-18.

Ozdamli, F., \& Uzunboylu, H. (2014). M-Learning adequacy and perceptions of students and teachers in secondary schools. British Journal of Educational Technology. doi: 10.1111/bjet.12136.

Rogers, Y. (2008). Using external visualizations to extend and integrate learning in mobile and classroom settings. In Visualization: Theory and practice in science education. Springer Netherlands.

Schlieder, C., Kiefer, P., \& Matyas, S. (2006). Geogames: Designing Location-based games from classic board games. IEEE Intelligent Systems, 21(5), 40-46.

Schrier, K. (2009). Reliving History with "Reliving the Revolution": Designing Augmented Reality Games to Teach the Critical Thinking of History. In R. Ferdig (Ed.), Handbook of Research on Effective Electronic Gaming in Education (pp. 1460-1476). Hershey, PA: Information Science Reference.

Pardo, A., \& Siemens, G. (2014). Ethical and privacy principles for learning analytics, British Journal of Educational Technology, 45(3), 438-450. 
Squire, K.D., \& Jan, M. (2007). Mad City Mystery: Developing scientific argumentation skills with a place-based augmented reality game on handheld computers. Journal of Science Education and Technology, 16(1), 5-29.

Tornero, R., Torrente, J., Moreno-Ger, P. \& Baltasar, M. (2010). e-Training DS: An Authoring Tool for Integrating Portable Computer Games in e-Learning. Advances in Web-Based Learning - ICWL, Lecture Notes in Computer Science, Springer Berlin: Heidelberg.

Wang, M., Shen, R., Novak, D., \& Pan., X. (2009). The impact of mobile learning on students' learning behaviours and performance: Report from a large blended classroom. British Journal of Educational Technology, 40(4), 673-695.

Yang, H.C. (2005). A general framework for automatically creating games for learning. In the Proceedings of the International Conference on Advanced Learning Technologies, 5-8 July 2005, Kaohsiung, Taiwan.

Please cite as:

Melero, J., Hernández-Leo, D., Sun, J., Santos, P., Blat, J. (2015) How was the activity? A visualization support for a case of location-based learning design, British Journal of Educational Technology, 46(2), 317-329. 